\title{
Genomic Medicine: Using Genetic Make-up of the Human Genome, AZQ was Designed to Treat Glioblastoma, the Brain Tumor
}

ISSN: 2637-773X

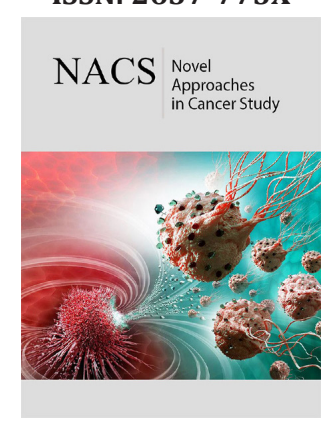

*Corresponding author: Hameed Khan, Department of Genetics \& Robotics, Bethesda, Maryland, USA

Submission: 啙 August 10, 2021

Published: 畊 August 18, 2021

Volume 6 - Issue 2

How to cite this article: Hameed Khan Genomic Medicine: Using Genetic Makeup of the Human Genome, AZQ was Designed to Treat Glioblastoma, the Brain Tumor. Nov Appro in Can Study. 6(2). NACS.000634. 2021.

DOI: 10.31031/NACS.2021.06.000634

Copyright@ Hameed Khan, This article is distributed under the terms of the Creative Commons Attribution 4.0 International License, which permits unrestricted use and redistribution provided that the original author and source are credited.

\author{
Hameed Khan* \\ Department of Genetics \& Robotics, USA
}

\section{Opinion}

I work on human Brain. The most complex organ in the Universe. I design drugs to treat Brain Cancer. Our Brain is a three-pound flesh that you can hold in the palm of your hand. It can contemplate the vast distances among billions of Galaxies across Universe; It can contemplate the concept of Infinity. It convinces us to believe in existence or non-existence of God. It questions our Ethics; our Morality, our Altruism and our Free-will. It is only a three-pound flesh and yet it can contemplate itself contemplating the meaning of life, asking questions. Questions like; Who are we? Where have we all come from? What was it that made us this way? How this Universe began? Why is it expanding at an accelerating speed? How is it likely to end? Are we alone in the entire Universe or there are other creatures who live in deep dark space of this vast Universe who may or may not look like us?

Our Brain is a three-pound flesh. It is made of 86 billion neurons. Each neuron is linked to other neuron by 10,000 to 100,000 connections called Synapses. Total number of Synapses, their combination and their permutations exceed the number of visible stars at night sky. Millions of Synapses join together to form Neuronal Circuit. That is where our memory is stored. Our memory connects our past present to our future. Through our five senses, we receive a billion bits of data each day. When we sleep, our Brain process the information. A small fraction of the information is retained in Hippo campus and Cerebral Cortex of our Brain, which is the library of our language and our Consciousness. The rest of the information is discarded. The retained information is restored, retrieved, cut, and paste and process faster than any computer. All the information is stored in Neuronal circuits and Cerebral Cortex of our Brain. Neuronal Circuits connects every neuron with every other neuron forming a Wiring Diagram linking the entire Brain. Millions of Neuronal Circuits interact to generate our thoughts and our ideas and our visions. The complexity of our Brain is the result of three and a half billion years of Biological Evolution. It is a perfect organ in the Universe. It is a seat of our consciousness.

One day something terrible happens to our Brain. A single molecule of a single nucleus of a single neuron is damaged by radiation, chemical/environmental pollution or Viral infection, or genetic inheritance, the whole Brain collapse like a house of card, it becomes non- 
functional. A single normal cell becomes abnormal leading to cancer forming a tumor called Glioblastoma, one of the deadliest forms of Brain cancer. Brain Cancer is very different from Liver or Lung cancer. For example, if a Liver cell is similar damaged by radiations or chemical/environmental pollutants. The damaged Liver cell will mutate, divide, multiply, replicate, differentiate, metastasize, invade, and spread, shutting genes after genes and organ after organ killing the patient. It takes years, but not Brain tumor. Glioblastoma is a solid and aggressive tumor. It grows so rapidly within months it becomes so large. Its sheer size will crush the synapses, crush the neuronal circuits and crush the wiring diagram and most patients will internally bleed to death within fourteen months.

One of the greatest challenges of nanotechnology is to seek out the very first abnormal cell in the presence of billions of normal cells of our Brain and shut off the genes before it spread. I worked on this assignment about a quarter of a century; conducted over 500 experiments which resulted in 200 novel drugs. They were all tested against experimental animal tumors. Forty-five of them were considered valuable enough to be patented by the US Government (US Patent 4, 146, 622 \& 4,233,215). One of them is AZQ which not only stop the growth of Glioblastoma, but also the tumor starts shrinking. For the discovery of AZQ, I was honored with, "The 2004 NIH Scientific Achievement Award." One of America's highest Award in Medicine. Complete lectures are available at https:// www.facebook.com/hameed.khan.7773/notes.

\section{Exhibit 1}

2004 NIH Scientific Achievement Award Presented to Dr. Hameed Khan by Dr. Elias Zerhouni, The Director of NIH during the NIH/APAO Award Ceremony held on December 3, 2004 (Figure 1). Dr. Khan is the Discoverer of AZQ (US Patent 4,146,622 \& 4,233,215), a Novel Experimental Drug Specifically Designed to shut off a Gene that causes Brain Cancer for which he receives a 17-year Royalty for his invention (License Number L-0I9-0I/0). To this date, more than 300 research papers have been published on AZQ. The award ceremony was broadcast live worldwide by the

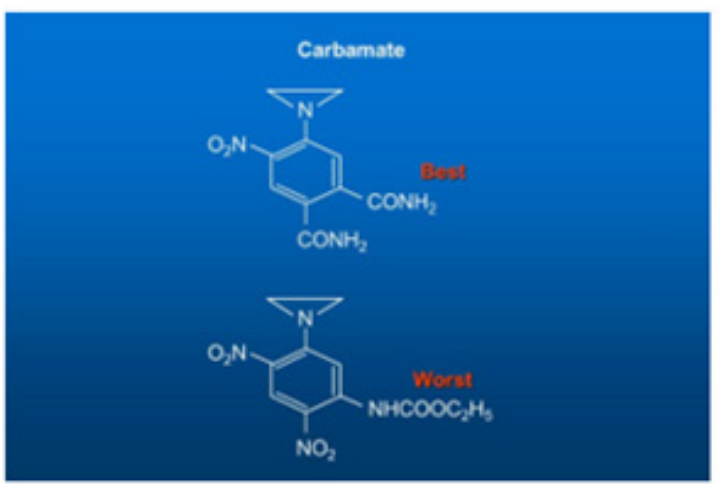

Voice of America (VOA). Dr. Khan is the first Indian to receive one of America's highest awards in Medicine.

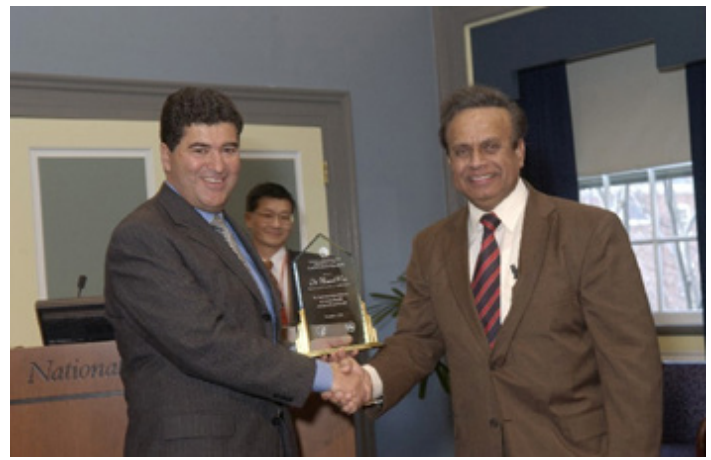

Figure 1

\section{Exhibit 2}

His Excellency, Dr. A.P.J. Abdul Kalam, The President of India Greeting Dr. A. Hameed Khan (Figure 2). Discoverer of anti-cancer AZQ after receiving 2004, Vaidya Ratna. The Gold Medal, One of India's Highest Awards in Medicine at the Rashtrapathi Bhavan (Presidential Palace), in Delhi, India, during a Reception held on April 2, 2004.

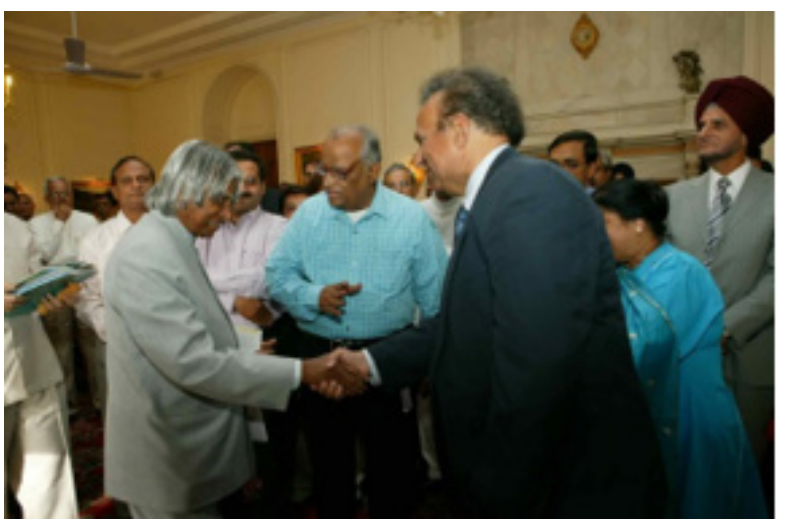

Figure 2

\section{Exhibit 3}

Single Strand DNA Binding Aziridine and Carbamate (Figure 3).

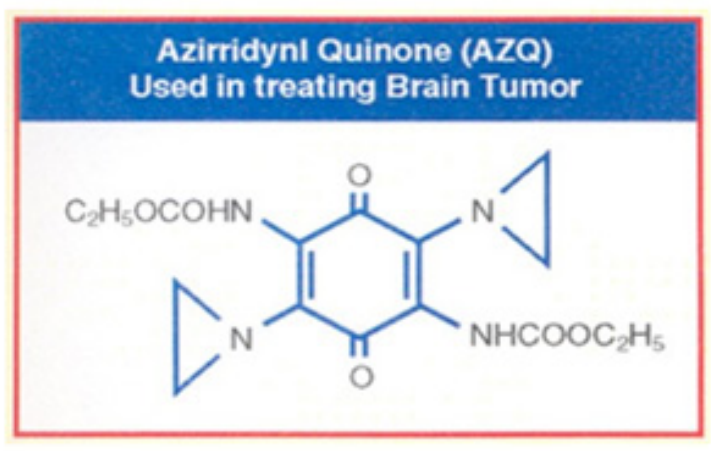

Figure 3 


\section{Exhibit 4}

Gold Medal for Dr. Khan (Figure 4).

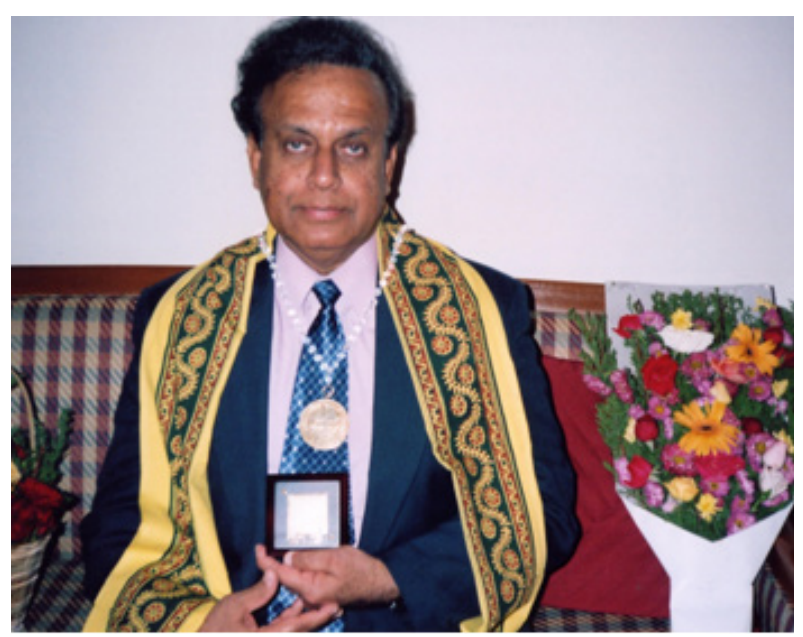

Figure 4 